\title{
Adjustable power supply assembly and training on the physics laboratory at YPK Masehi Berastagi
}

\author{
Kerista Tarigan $^{1 *}$, Timbangen Sembiring ${ }^{1}$, Widya Simamora ${ }^{1}$, Berto Simamora ${ }^{1}$, Robin \\ Simatupang ${ }^{1}$ \\ ${ }^{1}$ Departmet Physics, Faculty of Mathematics and Natural Science, Universitas Sumatera Utara \\ *Email:kerista@usu.ac.id
}

\begin{abstract}
Adjustable power supply assembly and training have been conducted to private YPK Berastagi high school students in Berastagi District, Karo. This activity was carried out in partnership with the University of North Sumatra in the form of community service. The purpose of the training and making of this study program is to improve the teaching activities of the theory and practice of the field of electronic physics to partners. The training and making of the study program were carried out using the theory understanding method, assembling and testing it. The main components and functions used are the $220 \mathrm{~V} 5 \mathrm{~A}$ step down transformer, $5 \mathrm{~A}$ rectifier diodes as dc rectifiers, $4700 \mu \mathrm{F}$ electrolyte capacitors as filters, and IC LM 317 regulators as voltage regulators and are equipped with current amplifiers, 2SA 73 transistors and 2SC 41 Based on test and analysis data obtained by students (i), the output voltage can be adjusted from $1.27-24.62$ volts with a maximum current of $3 \mathrm{~A}$. While the ripple voltage, $\mathrm{Vr} \mathrm{pp}=0.1$ Volt. obtained $\mathrm{mV}$. Based on the PS test results of assemblies against the burden of motorcycle lights, 40 Watt works well. Based on these results, the PS can be used.
\end{abstract}

Keyword: regulator, adjustable power supply, current booster, Transformator.

\begin{abstract}
Abstrak
Telah dilakukan kegiatan pelatihan dan pembuatan power supply (PS) kepada siswa (i) SMA swasta YPK Masehi Berastagi Kecamatan Berastagi, Karo. Kegiatan ini terlaksana atas kerjasama mitra dengan Universitas Sumatera Utara dalam wujud pengabdian kepada masyarakat. Tujuan pelatihan dan pembuatan PS ini adalah untuk meningkatkan kegiatan pengajaran teori dan praktek bidang fisika elektronika pada mitra. Pelatihan dan pembuatan PS tersebut dilakukan dengan metode pemahaman teori, merangkai dan mengujinya. Komponen dan fungsi utama yang digunakana adalah Transformator jenis step down $220 \mathrm{~V}$ 5A, Dioda rectifier 5A sebagai penyearah dc, kapasitor elektrolit sebesar $4700 \mu \mathrm{F}$ sebagai filter, dan regulator IC LM 317 sebagai pengatur tegangan serta dilengkapi dengan penguat arus, transistor 2SA 73 dan 2SC 41. Berdasarkan data pengujian dan analysis yang diperoleh siswa(i) diperoleh adalah, besar tegangan output dapat diatur dari 1,27 - 24,62 Volt dengan arus maksimal 3A. Sedangkan tegangan ripple, $\mathrm{Vr} p \mathrm{pp}=0,1$ Volt. diperoleh $\mathrm{mV}$. Berdasarkan hasil pengujian PS rakitan terhadap beban lampu sepeda motor, 40 Watt berhasil dengan baik. Berdasarkan hasil tersebut maka PS tersebut telah dapat dipergunakan.
\end{abstract}

Kata Kunci : regulator, adjustable supply, current booster, transformer

\section{PENDAHULUAN}

Perkembangan dunia elektronika telah dimulai ketika Thomas Alpha Edison (1883) menemukan filamen panas yang memancarkan elektron. Kemudian, Fleming (1904) mengembangkan dioda hampa dan diikuti oleh DeForest (1906) yang menambahkan elektroda ketiga untuk mendapatkan trioda hampa. Sehingga dari peristiwa tersebur sampai pada tahun 1950, maka tabung hampa telah mendominasi rangkaian elektronika yang banyak digunakan pada penguat, osilator, modulator dan sebagainya. Pada tahun 1948, komponen elektronika khususnya Transistor telah diketemukan oleh tiga orang sarjana fisika dari Amerika Serikat, yaitu W.H. Brattain, W. Shockley (1910-1989) dan J. Barden yang mereka lakukan di laboratorium Telephone Bell Amerika yang dipimpin oleh Shockley 1,2,3), Akibat penemuan tersebut maka pada tahun 1951 mulai berkembang industri dibidang semikonduktor yang menelan biaya multi-bilyun dollar dan meningkatnya penelitian 
yang akhirnya menghasilkan komponen diskrit maupun dalam bentuk IC seperti transistor, dioda dan piranti Optoelektronika, sensor, mikroprosessor dan sebagainya. Mengingat komponen tersebut telah tersedia di pasar maka dengan mempelajari sifat dan karakteristiknya maka dengan mudah dapat diharapkan untuk membuat rangkaian tidak saja PS arus searah (DCPS) akan tetapi dapat juga dikembangkan untuk eksperimen dan membuat instrumen elektronika lainnya.

Salah satu instrumen pendukung Lab. fisika bidang elektronik adalah catu daya listrik arus rata atau disebut juga dengan DCPS. Kebutuhan akan daya listrik pada Lab. fisika elektronika umumnya berkisar beberapa Watt dengan tegangan dari 1,5 - 12 Volt dengan arus milli Amper hingga beberapa Amper. Untuk menghindari penggunaan baterai kering yang kurang efisien, sekali pakai, harganya mahal, daya listriknya kecil. Disamping hal tersebut, pada akhir pemakaiannya akan menjadi limbah pada lingkungan. Untuk menghindari kekurangan penggunaan bateri kering tersebut maka dibutuhkan suatu power supply listrik dc yang lebih efektif, yaitu menggunakan sumber arus listrik jala PLN 220 VAC, frikuensi $50 \mathrm{~Hz}$ yang sudah tersedia. Tujuan pengabdian kepada masyarakat ini adalah untuk melatih dan membuat PS arus rata dalam rangka peningkatkan kompetensi siswa(i) pada Lab. Fisika elektronik. Berdasarkan jenisnya maka PS terdiri dari dua jenis yakni power supply linear dan power supply switching. Power supply linear berarti tegangan keluaran akan mengalir secara kontiniu ke beban. Sementara power supply switching merupakan power supply dengan teknik pensaklaran. Perbedaan istilah linear dan switching sangat berhubungan dengan penggunaan jenis regulator yang dipakai. Disamping itu, besar tegangan, arus, akurasi, kestabilan dan daya yang dibutuhkan dapat dikendalikan. Namun pada umumnya untuk keperluan Lab. Fisika elektronik dasar dapat dibuat dengan rangkaian DCPS yang linier karena lebih sederhana namun masih dalam batas performansi yang dapat diandalkan.

Struktur utama pada pembuatan rangkaian DCPS adalah terdiri dari 4 (empat) bahagian., yaitu transformator (sebagai penurun tegangan), rectifier atau penyearah gelombang ac menjadi pulsa dc, filter atau penapis sebagai pembentuk arus DC, dan regulator untuk mengatur tegangan yang diinginkan. Penyederhanaan struktur DCPS diperlihatkan seperti pada Gambar 1.1.

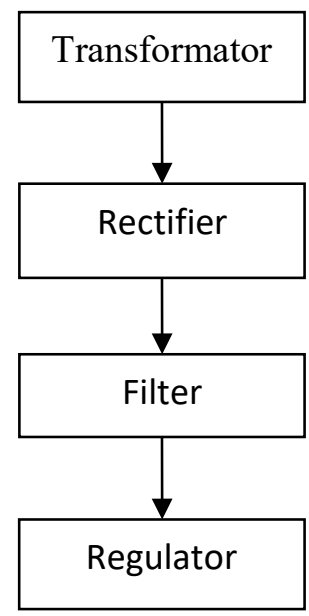

Gambar 1.1. Alur kerja Power Supply

\subsection{Transformator}

Transformator adalah suatu komponen yang terdiri dari inti besi yang dililiti dengan kabel yang dilapisi bahan isolator pada bahagian primer dan sekundernya. Berdasrkan prinsip Elektromagnetika diketahui bahwa jika kabel lilitan dialiri arus listrik ke satu bahagian maka bahagian yang lain akan terjadi induksi. Proses induksi elektromagnetik tersebut ditunjukkan pada Gambar 1.2. 


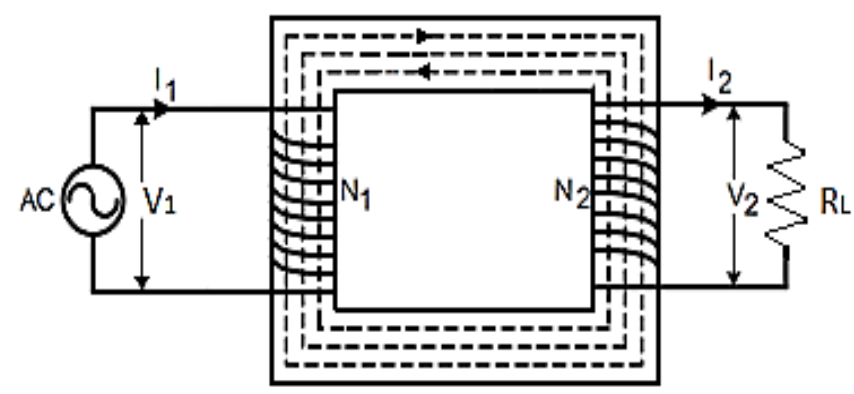

Gambar 1.2. Konsep Induksi Pada Tranformator

Berdasarkan konsep tersebut maka umumnya trafo dapat dipergunakan sebagai penurun dan penaik tegangan. Dengan demikian, jika suatu trafo dipergunakan untuk menurunkan tegangan, $V_{P}$ ke tegangan yang lebih rendah, $\mathrm{V}_{\mathrm{S}}$ maka jumlah lilitan pada sekundernya akan lebih sedikit dibandingkan pada lilitan primernya. Hal ini sesuai dengan rumusan pada persamaan tegangan, arus seperti berikut ini, yaitu

$$
\frac{N p}{N s}=\frac{V p}{V s}=\frac{I_{s}}{I_{p}}
$$

Dimana, $\mathrm{N}_{\mathrm{P}}$ dan $\mathrm{I}_{\mathrm{P}}$ adalah jumlah lilitan dan besar arus pada bahagian primer, $\mathrm{N}_{\mathrm{S}}$ dan $\mathrm{I}_{\mathrm{S}}$ adalah jumlah lilitan dan besar arus pada sekunder. oleh perbandingan jumlah lilitnnya.

\subsection{Rectifier}

Rectifier adalah komponen dioda yang khusus dipergunakan sebagai penyearah, yaitu untuk menyearahkan gelombang dari bentuk bolak balik (AC) menjadi bentuk setengah gelombang yang searah (DC). Bentuk sambungan dan simbol ditunjukkan seperti pada Gambar 1.3.

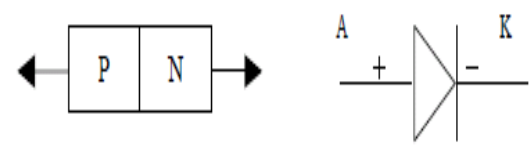

Gambar 1.3. Konstruksi dan Simbol Dioda

\subsection{Filter}

Filter adalah suatu rangkaian yang berfungsi untuk menghilangkan arus/tegangan kerut yang dihasilkan oleh dioda penyearah berupa pulsa-pulsa setengah gelombang menjadi gelombang arus/tegangan yang rata, dc. Salah satu rangkaian filter yang sederhana adalah rangkaian yang menggunakan komponen R dan C seperti pada Gambar 1.4.

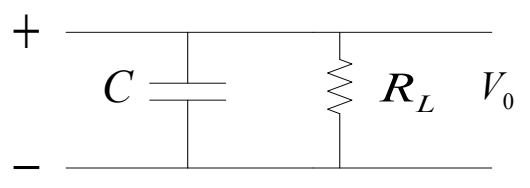

Gambar 1.4. Rangkaian filter RC

Untuk penyearah gelombang penuh dan dengan filter RC maka bentuk tegangan keluarannya akan seperti Gambar 1.5. 


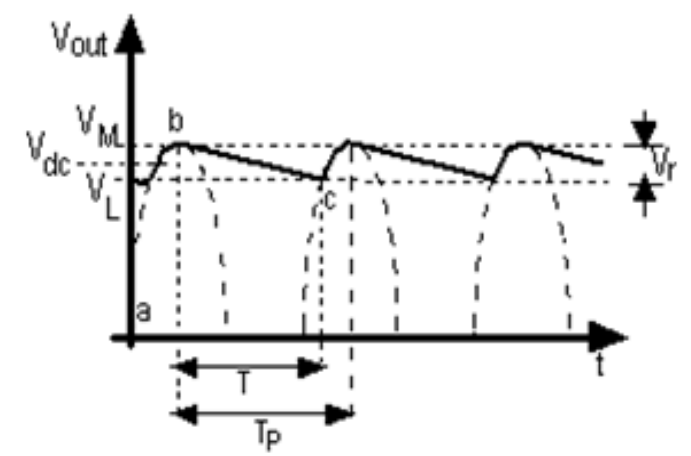

Gambar 1.5. Bentuk Keluaran Output Filter

Sedangkan besar tegangan gelombang penuh dc dengan filter RC adalah:

$$
V_{d c(F W)}=\frac{2 V_{p}}{\pi}
$$

dan frekuensi gelombang outputnya adalah:

$$
f_{\text {output }}=2 f_{\text {input }}
$$

Sedangkan, ketika dipasang filter maka terjadi pengurangan tegangan kerutnya. Hal ini disebabkan karena kapasitor memerlukan waktu $\tau=\mathrm{RC}$ detik untuk mengosongkan muatannya. Sebelum tegangan pada kapasitor turun drastis ke tegangan nol, tegangan pada kapasitor keburu naik lagi. Tegangan yang berubah yang terjadi disebut dengan tegangan riak, dengan nilai puncakke-puncak dinyatakan sebagai . Kualitas rangkaian filter umumnya dinyatakan oleh nisbah riak puncak-ke-puncak, peak to peak ripple ratio, pprr, yaitu:

$$
\text { pprr }=\frac{V_{r p p}}{V_{d c, \text { rata-rata }}}
$$

Dengan demikian, besar tegangan $\mathrm{V}_{\text {rpp }}$ untuk penyearah gelombang penuh adalah:

$$
V_{r p p}=\frac{V_{p}}{2 f R_{L} C}
$$

\subsection{Regulator}

Regulator adalah komponen yang berfungsi sebagai pengatur tegangan agar tegangan keluaran yang tetap stabil. Ada berbagai macam jenis regulator. Salah satu dioda yang paling sederhana dan ukuran yang sangat kecil adalah diode Zener, seperti contoh pada Gambar 1.6.

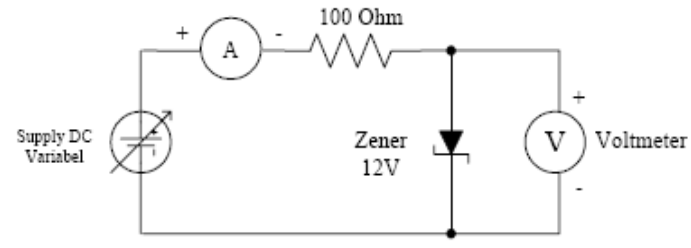

Gambar 1.6. Diode Zener

Belakangan ini, regulator yang banyak digunakan adalah regulator yang dalam bentuk IC seperti IC seri 78xx/79xx, LM 317 dan sebagainya. Kehandalan regulator ini adalah tegangan, arus keluarannya mudah untuk di atur. 


\subsection{Transistor}

Transistor adalah suatu komponen aktif yang terbuat dari bahan semikonduktor, seperti Si dan Ge yang umumnya digunakan untuk berbagai komponen seperti dioda, transistor dan IC . Umumnya transistor digunakan sebagai penguat daya dan sakelar, switching. Prinsip kerja transistor pada dasarnya adalah hampir sama dengan dioda namun ditambah dengan suatu pin base sebagai pengatur laju arus dari arah kolektor menuju emiter. Simbol transistor diperlihatkan seperti pada Gambar 1.7.
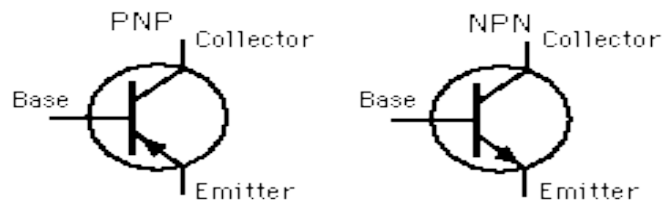

Gambar 1.7. Simbol Transistor Tipe PNP dan NPN

\section{METODE PELAKSANAAN}

Metode pembuatan PS adalah berdasarkan prosedur rangkaian dasar dengan menganti komponen regulator dan penguat arus sesuai dengan alur pada Gambar 1.1. Berdasarkan Gambar 1.1 tersebut maka di rangkai dari satu bahagian ke bahagian berikutnya dengan komponen masing-masing yang disesuaikan, yaitu terutama pada bahagian penyearah dan regulator serta penguat arus. Sedangkan penyearah yang dibuat adalah penyearah gelombang penuh dari keluaran trafo yang menggunakan sistem Bridge, yaitu dengan 4 (empat) buah dioda dengan besaran masing-masing 5A seperti pada Gambar 2.1.

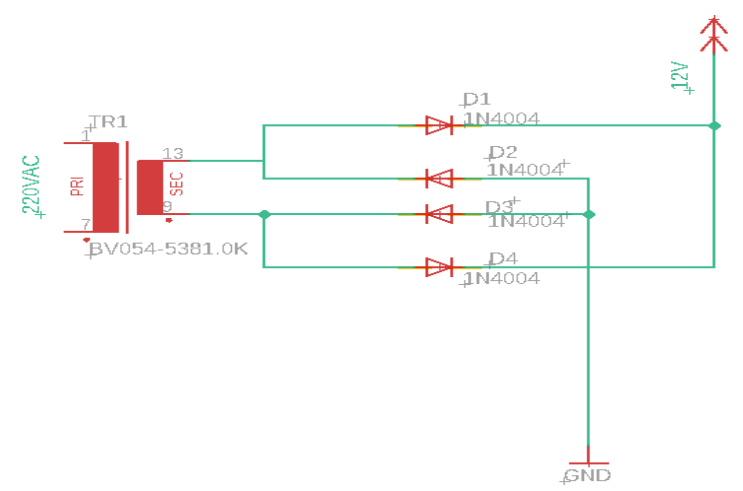

Gambar 2.1. Rangkaian Trafo dengan Penyearah Bridge

Sedangkan, regulator yang dibuat adalah regulator dari IC LM 3178) yang dilengkapi dengan penguat arus menggunakan transistor 2SA 733 dan 2SC 41serta dilengkapi dengan diode sebagai protector arus balik seperti pada Gambar 2.2. 


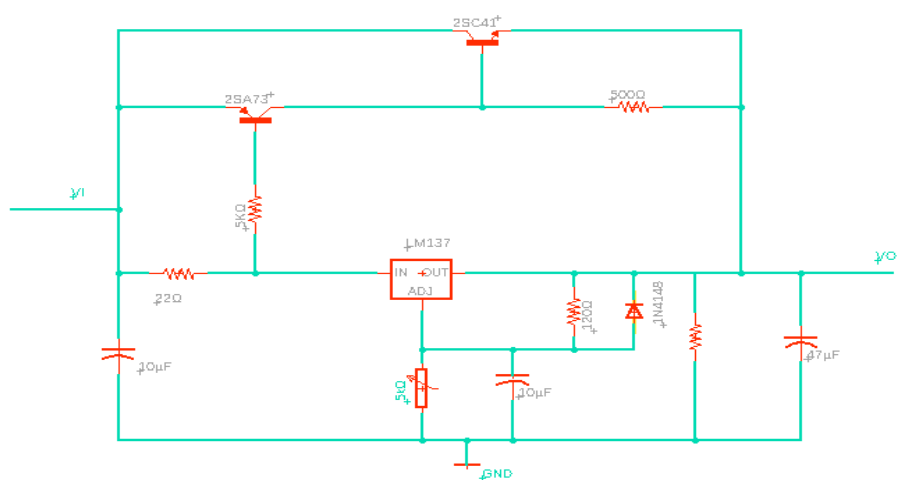

Gambar 2.2. Rangkaian Regulator dan Penguat Arus

\section{HASIL DAN PEMBAHASAN}

\subsection{Data Pengukuran}

Data pengukuran diperoleh adalah berdasarkan rangkaian lengkap yang telah dirangkai oleh siswa(i) seperti pada Gambar 3.1 (a) dan hasil konstruksinya adalah seperti pada Gambar 3.1(b).

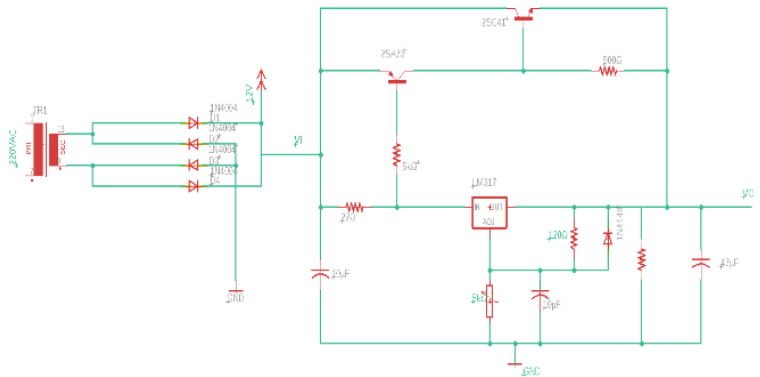

(a)

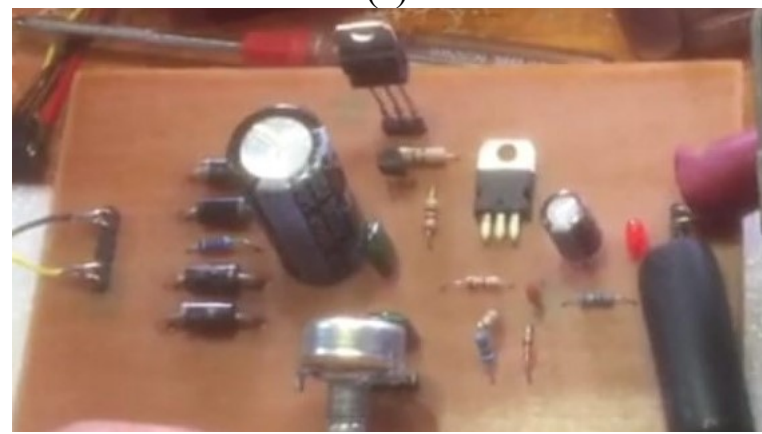

(b)

Gambar 3.1. Rangkaian DCPS (a) dan Prototipe Fisik (b).

Pengukuran data dilakukan di beberapa titik pengukuran, diantaranya adalah tegangan pada input/output trafo, dioda, filter, bentuk gelombang dan arus keluaran dengan beban, yaitu masingmasing adalah: $\mathrm{V}_{\text {in Trafo }}=220 \mathrm{~V}, \mathrm{~V}_{\text {out Dioda }}=, \mathrm{V}_{\text {out Filter }}=, \mathrm{V}_{\text {ripple Regulator }}=$. sedangkan tegangan output regulator dapat di atur, $\mathrm{V}_{\text {out Regulator }}=1,271-24,62$ Volt dan besar arus hingga 3A seperti pada Gambar 3.2(a) (tegangan minimal) dan 3.2(b) (tegangan maksimal). 


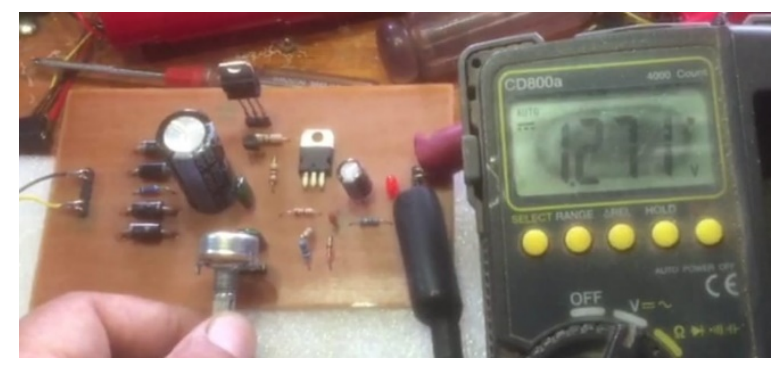

(a)

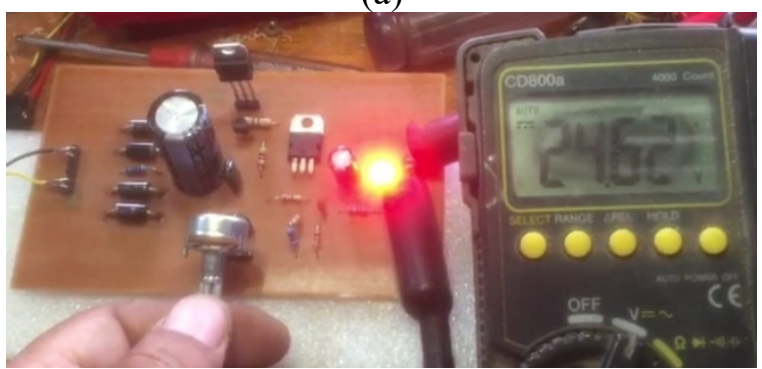

(b)

Gambar 3.2. Penunjukan Besar Tegangan PS

Prototipe PS hasil rakitan pada pelatihan dan pembuatan dengan mitra ditunjukkan seperti pada Gambar 3.3 berikut ini.

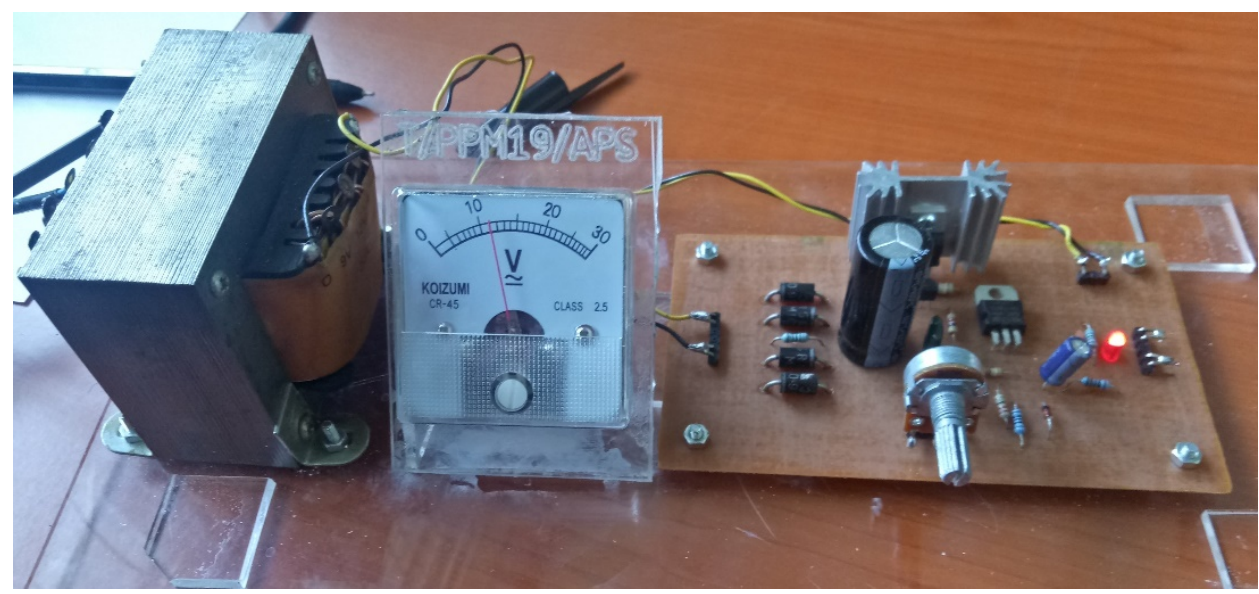

Gambar 3.3. Prototipe Rakitan PS

Sedangkan hasil display osiloskop pada keluaran dioda penyearah bridge dan tegangan ripple filter diperlihatkan pada Gambar 3.4 dan Gambar 3.5. 


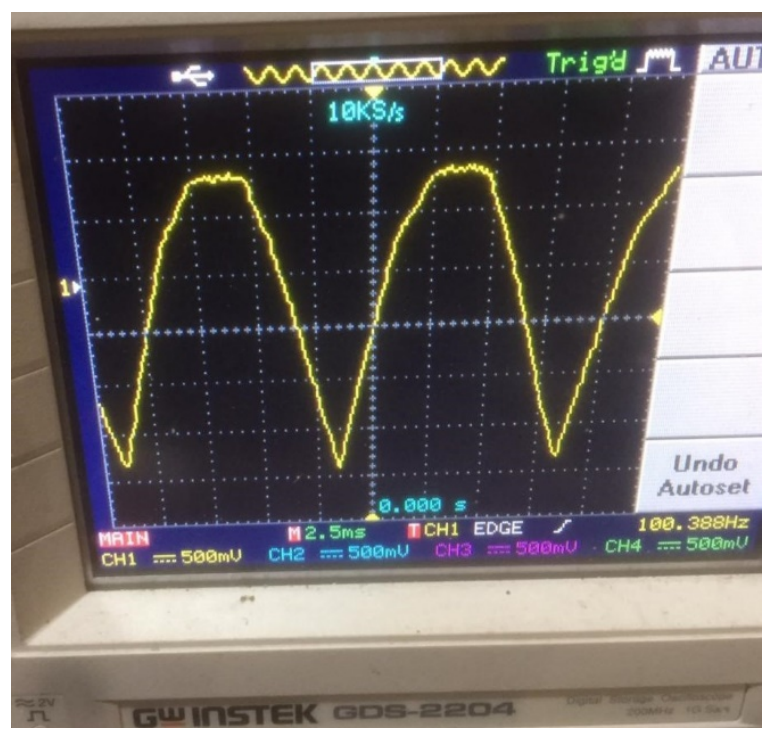

Gambar 3.4. Gelombang Output Penyearah

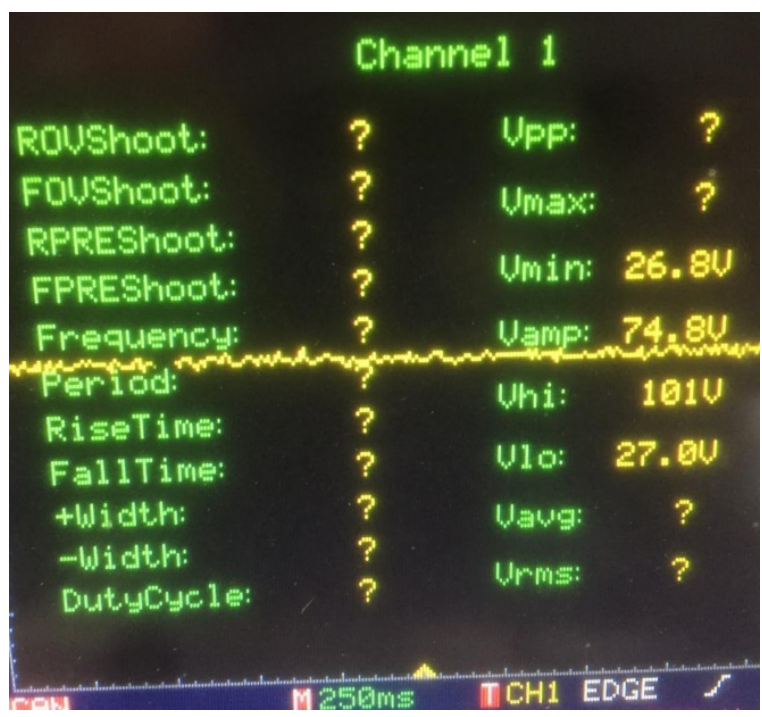

Gambar 3.5. Tegangan Ripple

\subsection{Analisis Data}

Dari rangkaian pada Gambar 10,11dan 12 maka tegangan yang dihasilkan sesuai dengan hasil secara teori dan praktek, namun pada keadaan tertentu nilai tegangan output kurang stabil. Ketidak stabilan tersebut diakibatkan oleh tegangan jala PLN yang terkadang drop hingga $20 \mathrm{~V}$, atau hanya 200 VAC. Namun dalam keadaan stabil diperoleh besaran: $V_{\text {itrafo }}=215$ V. Berdasarkan data pengukuran analisis data maka diperoleh besar tegangan maksimum adalah sebagai berikut.

$$
\begin{aligned}
& \mathrm{V}_{\text {out D rec }}=18,2 \mathrm{~V} \\
& \mathrm{~V}_{\text {elco }}=25,3 \mathrm{~V} \\
& \mathrm{~V}_{\text {reg }}=1,27-24,62 \text { Volt. } \\
& \mathrm{V}_{\text {r pp }}=0,1 \text { Volt. }
\end{aligned}
$$

Sedangkan, besar arus maksimum pada beban bohlam $40 \mathrm{~W}$ adalah $3 \mathrm{~A}$. 


\section{KESIMPULAN}

Hasil pelatihan dan pembuatan DCPS telah berhasil dengan sangat baik. Hal ini ditunjukkan dengan adanya rangkaian dan prototipe yang telah dibuat. Berdasrkan hasil analisis Prototipe/alat tersebut menghasilkan tegangan yang dapat diatur mulai dari 1,27-24,62 Volt dengan arus maksimum $3 \mathrm{~A}$ dan tegangan ripplenya sekitar $0,1 \mathrm{Volt}_{\mathrm{pp}}$. Dengan demikian, alat yang dibuat dapat dipergunakan dengan baik. Penggunaan alat tersebut disarankan untuk tidak menggunakan beban yang melampaui arus 3A, hal ini untuk menghindari IC Regulator panas yang berlebih.

\section{UCAPAN TERIMAKASIH}

Pengabdian Kepada Masyarakat dibiayai oleh NON PNBP USU sesuai Kontrak Pelaksanaan Pengabdian Kepada Masyarakat, Program Mono Tahun, Tahun Anggaran 2019 Nomor: 327/UN5.2.3.2.1/PPM/2019 Tanggal 20 Mei 2019.

\section{DAFTAR PUSTAKA}

Data Sheet https://www.alldatasheet.com/datasheet pdf/pdf/22749/STMICROELECTRONICS/LM317.html

Floyd, Thomas L., 1995. Electronics Fundamentals, Circuits, Devices, and Application. Prentice Hall, Englewood Cliffs, New Jersey, Colombus, Ohio.

https://www.electronics-tutorials.ws/blog/variable-voltage-power-supply.html

https://www.sciencedirect.com/topics/engineering/common-power-supply

Instructables:Designof an Unregulated Power Supply https://www.instructables.com/id/Design-ofan-Unregulated-Power-Supply/

Louis E. Frenzeljr., 2018. Electronic Circuits: Linear/Analog

Power_supply

https://www.st.com/content/ccc/resource/technical/document/application_note/d9/cb/37/7c/05/ ba/42/40/CD00003794.pdf/files/CD00003794.pdf/jcr:content/translations/en.CD00003794.pdf

Sutrisno, 1986. Elektronika Teori Dasar dan Penerapannya, ITB Bandung.

Wikipedia https://en.wikipedia.org/wiki/Power_supply 